\title{
Utilization of Corn Oil through Water Degumming Process for Lecithin Emulsifier Production
}

\author{
Fahmi Arifan*, Muhammad Kelvin Nandita, Enrico Fendy Sapatra, and Salsabila Salsabila \\ Department of Industrial Chemical Engineering Technology, Vocational School, Diponegoro University, \\ Jl. Prof. H. Soedarto, SH, Tembalang, Semarang 50275, Central Java, Indonesia
}

* Corresponding author:

tel: $+62-8156520216$

email:fahmiarifan@live.undip.ac.id

Received: April 8, 2021

Accepted: August 30, 2021

DOI: $10.22146 /$ ijc. 65195

\begin{abstract}
Lecithin is an emulsifier that plays an active role in reducing surface tension in making emulsions. The production of lecithin from other vegetable oils allows the use of other types of vegetable oil as a source of lecithin production to replace soy-based oil, which has begun to be used as a bioenergy raw material. This study aims to find an alternative source of new lecithin derived from corn oil by knowing the characteristics of lecithin and applied to mayonnaise. The resulting lecithin was used in mayonnaise with a 2 factorial randomized block design method consisting of 3 levels. Based on the results obtained, the characteristic of corn oil lecithin is that the largest content is hexadecanoic acid which is $44.79 \%$, and the strongest vibration band is $\mathrm{CH}_{2}$ vibration with stretching modes of symmetry and asymmetry at 2922 and $2853 \mathrm{~cm}^{-1}$ and the terminal $\mathrm{CH}_{3}$ group in the $1374 \mathrm{~cm}^{-1}$. L3C3 treatment was the best result with $60 \% \mathrm{fat}$ content, $4 \%$ emulsion stability, $2.12 \mathrm{cP}$ viscosity, and $1.42 \times 10^{-3} \mathrm{~N} / \mathrm{m}$ surface tension. Organoleptic showed a preference value, namely color 4.4 (like), taste 3.2 (sufficient like), smell 4 (like), and texture 3.80 (like it).
\end{abstract}

Keywords: corn lecithin; water degumming; mayonnaise

\section{- INTRODUCTION}

Food is anything that comes from biological sources and water, whether it is processed or not, which is intended as food or drinks for human consumers, including food additives and other materials used in preparing, processing, and making food or drinks [1]. Phosphatidylcholine (PC), phosphatidylethanolamine (PE), and phosphatidylinositol (PI) are acetone-insoluble phosphatides. They are mixed with other substances such as triglycerides, fatty acids, and other minor compounds to form lecithin [2]. Lecithin or phosphatidylcholine is an important natural emulsifier found widely in many food fields [3]. However, commercial lecithin comes from the isolation of animal organs such as pigs which are haram. Lecithin derived from commercial vegetable oils comes only from soybean oil. Therefore, the production of lecithin from other vegetable oils can be a solution for the availability of halal vegetable lecithin such as corn oil and allows the use of other types of vegetable oil as a source of lecithin production to replace soybean-based oil, which has begun to be used as raw material for bioenergy or in the field of food diversification [4]. Based on previous research studies, corn oil can be used as raw material for making lecithin. Corn oil contains $0.7-2.0 \%$ gum phosphatide, which is commonly used to produce crude lecithin. This amount is greater than coconut oil and palm oil [5]. The degumming step in the refining of crude oils extracted from soybean, rapeseed, sunflower, and corn germ, among others, yields lecithin [6].

Lecithin can be used as an emulsifier in a broad range of emulsions. However, its multicomponent nature limits its versatility [7]. Therefore, the lecithin obtained is expected to be applied as an emulsifier, one of which is mayonnaise (an oil-in-water emulsion) [8]. Mayonnaise is a food product in the form of an emulsion which is currently well known as a sauce used in salads, sandwiches, and other foods. Although the emulsifier that has been used by mayonnaise is egg yolk, one of the efforts to reduce the fat content in mayonnaise is to reduce the use of egg yolk by using other emulsifiers. 
Using an emulsifier other than egg yolk can reduce overall fat content and increase stability [9]. This study aims to determine the production of vegetable lecithin from corn oil through a water degumming process and find alternative sources of new lecithin derived from corn oil by knowing the characteristics of lecithin and applying it to mayonnaise to determine the effect on physical, chemical, and organoleptic properties.

\section{- EXPERIMENTAL SECTION}

\section{Materials}

The materials used were corn oil (100\% purity, conducted from CV. KIE Food Industry), distilled water, cooking oil, $\mathrm{CMC}, \mathrm{H}_{2} \mathrm{SO}_{4}$ (98\% purity Merck, Germany), salt, and sugar.

\section{Instrumentation}

Magnetic stirrer and centrifuge used to extract gum (crude corn lecithin) by following previously reported procedure [4]. In addition, gas Chromatography-Mass Spectrometry (GC-MS) and Fourier Transform Infra-Red (FT-IR) were applied for analysis and corn lecithin characterization.

\section{Procedure}

\section{Steps to make gum (crude corn lecithin)}

Extracting gum from corn oil was carried out by mixing $250 \mathrm{~mL}$ of corn oil with distilled water $(15 \mathrm{~mL})$, then heated at a temperature of $80^{\circ} \mathrm{C}$, were kept constant, and stirred for $2 \mathrm{~h}$. In this process, a clear colored layer will be obtained, which will be taken and dried. The result of this drying is called gum. The clear layer obtained from heating was separated using a centrifuge at $500 \mathrm{rpm}$ for $20 \mathrm{~min}$. The thin layer obtained after the centrifuge process was then dried using an oven with a temperature of $90.5^{\circ} \mathrm{C}$ for 5 days [10].

\section{Step to make mayonnaise}

Mayonnaise was made using a 2 factorial randomized block design method consisting of 3 levels. Factorial 1 was the addition of lecithin emulsifier with a weight of 0,20 , and $30 \mathrm{~g}$, while factorial 2 was the addition of CMC with 0,20 , and $30 \mathrm{~g}$ that 9 treatment combinations were obtained with 3 replications.

\section{Corn lecithin characteristics test phase}

The $10 \mathrm{~mL}$ of corn lecithin obtained from corn oil were tested using GC-MS to determine the acyl lecithin chain structure. In addition, an FTIR was used to determine the functional groups of corn lecithin emulsifiers.

\section{Mayonnaise test phase with the addition of corn lecithin and CMC}

Mayonnaise with the addition of corn lecithin and $\mathrm{CMC}$ was tested for its physical, chemical properties in the form of fat content, emulsion stability, viscosity, and immersion stress, and an organoleptic test as well. Data analysis was performed using ANOVA with a 5\% confidence interval. If there is an interaction between factors, it is continued into the DMRT (Duncan Multiple Range Test) tests. The selection of the best treatment used Multiple Attributes.

\section{- RESULTS AND DISCUSSION}

\section{Analysis of the Characteristics of Corn Lecithin Emulsifier}

Corn lecithin emulsifier was tested in advance using GC-MS to determine the content of the corn lecithin emulsifier. Testing by GC-MS to determine the content of corn lecithin is considered effective because it does not require a longer retention time, and the results can be proven accurate. Analysis by GC-MS was carried out to determine the acyl chain structure of lecithin [11]. The GC-MS test result data is presented in tabular form and shown in Table 1.

From Table 1, it can be seen that the content of corn lecithin emulsifier through the results of mass spectroscopic analysis of each of these peaks shows a fragmentation pattern of $0.09 \%$ lauric acid (dodecanoic acid), $0.94 \%$ myristic acid (tetradecanoic acid), 44.79\% palmitic acid (hexadecanoic acid), 40.08\% oleic acid (9octadecenoic acid (Z)-), 5.99\% stearic acid (octadecanoic acid), $\quad 1.83 \%$ oxiraneoctanoic acid and $1.66 \%$ oxiraneoctanoic acid. From these results, it can be seen that the fatty acid residues of the phospholipids, GC-MS results correspond to the fatty acid components present in corn oil. Corn oil contains palmitic acid, linoleic acid, stearic acid, linolenic acid, and oleic acid [12]. From the 
Table 1. The emulsifying component of corn lecithin is the GC-MS test result

\begin{tabular}{lccll}
\hline No & R. Time & Content $(\%)$ & Component name & $\begin{array}{l}\text { Structural } \\
\text { formulas }\end{array}$ \\
\hline 1 & 28.23 & 0.09 & Dodecanoic acid & $\mathrm{C}_{13} \mathrm{H}_{26} \mathrm{O}_{2}$ \\
2 & 34.06 & 0.94 & Tetradecanoic acid & $\mathrm{C}_{15} \mathrm{H}_{30} \mathrm{O}_{2}$ \\
3 & 39.406 & 44.79 & Hexadecanoic acid & $\mathrm{C}_{17} \mathrm{H}_{34} \mathrm{O}_{2}$ \\
4 & 43.44 & 40.08 & 9-Octadecenoic acid (Z)- & $\mathrm{C}_{19} \mathrm{H}_{36} \mathrm{O}_{2}$ \\
5 & 44.08 & 5.99 & Octadecanoic acid & $\mathrm{C}_{19} \mathrm{H}_{38} \mathrm{O}_{2}$ \\
6 & 47.22 & 1.83 & Oxiraneoctanoic acid, 3-octyl-, methyl ester, cis- (CAS) & $\mathrm{C}_{19} \mathrm{H}_{36} \mathrm{O}_{3}$ \\
7 & 47.44 & 1.66 & 2-Oxiraneoctanoic acid, 3-octyl-, methyl ester (CAS) & $\mathrm{C}_{19} \mathrm{H}_{36} \mathrm{O}_{3}$ \\
\hline
\end{tabular}

table, we can also see that the largest content of corn lecithin emulsifier is palmitic acid (hexadecanoic acid) which is $44.79 \%$. Thus, the isolated phospholipids from corn oil gum have a polar and a non-polar part. In the research conducted by the compilers, only the non-polar parts were analyzed using GC-MS analysis, which results had components that matched the components of corn oil so that this part could dissolve in the oil. The things above cause the phospholipids to easily be on the interface of corn oil and water so that the emulsion that is formed is relatively stable [13].

Furthermore, corn lecithin was tested using FTIR to determine its functional groups from the corn lecithin emulsifier. Fourier transforms infrared (FTIR) spectroscopy is widely used to authenticate certain food products [14]. FTIR instruments have many advantages over conventional dispersive instruments, with more energy yield, excellent wavenumber reproducibility and accuracy, broad and precise spectral manipulation capabilities, and advanced chemometric software to handle calibration development [15]. The FTIR spectrum of corn lecithin emulsifier is shown in Fig. 1.

The FTIR results in Fig. 1 show that the strongest band is $\mathrm{CH}_{2}$ vibrations with the symmetrical strain mode and asymmetry at 2922 and $2853 \mathrm{~cm}^{-1}$. This wavenumber is usually "sensitive to conformation" it is affected by changes in the trans/gauche conformation ratio in the acyl chain. There is also an absorption band for the terminal $\mathrm{CH}_{3}$ groups in the area $1374 \mathrm{~cm}^{-1}$. Vibration for the ester groups, especially for the $\mathrm{C}=\mathrm{O}$ stretch, appears in the region of $1742.49 \mathrm{~cm}^{-1}$. The vibration for the anhydride, especially for the $\mathrm{C}-\mathrm{O}$ stretch, appears in the $1159.07 \mathrm{~cm}^{-1}$ regions. The result shows that the corn lecithin emulsifier has almost the same absorbance pattern in the specific absorption regions for lecithin. The IR spectra for lecithin can be divided into spectral regions arising from the vibrations of the lipophilic tail molecule, the interface region, and the head group [14].

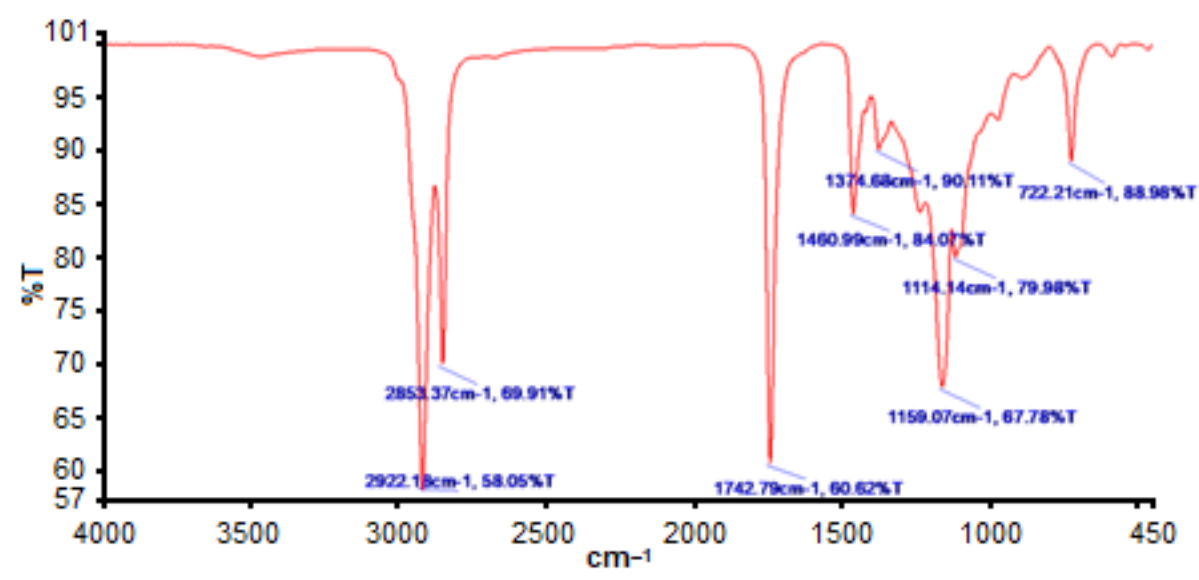

Fig 1. FTIR spectra of corn lecithin emulsifier 


\section{Analysis of mayonnaise with the addition of Corn Lecithin Emulsifier}

\section{Analysis of fat content in mayonnaise}

Mayonnaise sauce is one of the oldest and most used in the food world, accompanying popular salads, seafood, and filling sandwiches. Nevertheless, one main problem with egg yolk is its high cholesterol content [16]. Therefore, the product expected from using Corn Lecithin is to reduce the fat content contained and produce the desired product, namely using vegetable lecithin. Although the emulsifier that has been used is egg yolk, one of the efforts to reduce the fat content in mayonnaise is to reduce the use of egg yolk by using other emulsifiers. Using an emulsifier other than egg yolk can reduce overall fat content and increase stability [17]. The value of the fat content (\%) in mayonnaise is shown in Table 2.

Table 2 shows that the highest fat content was found in adding emulsifier corn lecithin and CMC to L3C3 treatment of $60 \%$, which in $\mathrm{L} 3 \mathrm{C} 3$ treatment used $30 \mathrm{~g}$ Corn Lecithin independent variables and $30 \mathrm{~g} \mathrm{CMC}$. The theory suggests that the higher the lecithin and CMC emulsifier added, the higher the fat content. The increase in fat content is due to the increasing concentration of lecithin emulsifier, increasing the hydrophobic group, which affects mayonnaise fat content. Lecithin is an emulsifier that tends to be non-polar, which has a hydrophobic group as a fat-binding group and a hydrophilic one as a water-binding group [18]. The fat content of standard mayonnaise on the market is $80.73 \%$ [19], whereas, in the research conducted by the author, the $\mathrm{L} 3 \mathrm{C} 3$ treatment found $60 \%$ results, which means that it is still far below the standard to be marketed. However, when compared with the quality requirements of mayonnaise (SNI 01-4473-1998), which is at least 65\%, the results of this research are almost approaching SNI.

Based on the analysis of the fat content in mayonnaise, the variable has an average value of 41.66 and a standard deviation of 13.95 . The results showed that the standard deviation value was smaller than the value average.

\section{Emulsion stability analysis on mayonnaise}

Emulsification processes also improve the texture, stability, and shelf-life of food products [20]. The product that is expected from the use of Corn Lecithin is good emulsion stability. Lecithin as an emulsifier can stabilize oil and water, which is clear from its structure. Emulsion stability is also influenced by particle size, type, and quantity of emulsifier, the density difference between the two phases, particle movement, and viscosity of the external phase. Using an emulsifier other than egg yolk can reduce overall fat content and increase stability [9]. The emulsion stability value (\%) in mayonnaise is shown in Table 3.

Table 2. Fat content (\%) in mayonnaise with the addition of corn lecithin emulsifier

\begin{tabular}{lccccc}
\hline $\begin{array}{c}\text { Run } \\
(\text { Code })\end{array}$ & $\begin{array}{c}\text { Lecithin } \\
(\mathrm{g})\end{array}$ & $\begin{array}{c}\text { CMC } \\
(\mathrm{g})\end{array}$ & $\begin{array}{c}\text { Readable volume } \\
(\mathrm{mL})\end{array}$ & $\begin{array}{c}\text { Sample volume } \\
(\mathrm{mL})\end{array}$ & $\begin{array}{c}\text { Fat level } \\
(\%)\end{array}$ \\
\hline L1C1 & 0 & 0 & 1 & 5 & 20 \\
L1C2 & 0 & 20 & 1.2 & 5 & 24 \\
L1C3 & 0 & 30 & 1.3 & 5 & 26 \\
L2C1 & 20 & 0 & 2 & 5 & 40 \\
L2C2 & 20 & 20 & 1 & 2 & 50 \\
L2C3 & 20 & 30 & 1 & 2 & 50 \\
L3C1 & 30 & 0 & 1 & 2 & 50 \\
L3C2 & 30 & 20 & 1.1 & 2 & 55 \\
L3C3 & 30 & 30 & 1.2 & & $60^{*}$ \\
\hline Average & & & &
\end{tabular}

Fahmi Arifan et al. 
Table 3. Emulsion stability (\%) in mayonnaise with the addition of an emulsifier corn lecithin

\begin{tabular}{lccccc}
\hline $\begin{array}{c}\text { Run } \\
(\text { Code })\end{array}$ & $\begin{array}{c}\text { Lecithin } \\
(\mathrm{g})\end{array}$ & $\begin{array}{c}\text { CMC } \\
(\mathrm{g})\end{array}$ & $\begin{array}{c}\text { Separate volume } \\
(\mathrm{mL})\end{array}$ & $\begin{array}{c}\text { Sample volume } \\
(\mathrm{mL})\end{array}$ & $\begin{array}{c}\text { Emulsion } \\
\text { stability }(\%)\end{array}$ \\
\hline L1C1 & 0 & 0 & 9.9 & 10 & 1 \\
L1C2 & 0 & 20 & 9.8 & 10 & 2 \\
L1C3 & 0 & 30 & 9.75 & 10 & 2.5 \\
L2C1 & 20 & 0 & 9.78 & 10 & 2.2 \\
L2C2 & 20 & 20 & 9.77 & 10 & 2.3 \\
L2C3 & 20 & 30 & 9.76 & 10 & 2.4 \\
L3C1 & 30 & 0 & 9.68 & 10 & 3.2 \\
L3C2 & 30 & 20 & 9.65 & 10 & 3.5 \\
L3C3 & 30 & 30 & 9.6 & 10 & $4^{*}$ \\
\hline Average & & & & 2.56 \\
SD & & & & & 0.83 \\
\hline
\end{tabular}

Note: $\left(^{*}\right)=$ The best result

Table 3 shows that there are differences in the stability of using emulsifiers. In the table above, it shows that the L3C3 treatment has a high level of stability of $4 \%$ because the addition of $30 \mathrm{~g}$ lecithin causes the emulsion to be more stable compared to the addition of other lecithin's, which is indicated by the less oil that separated at the time of centrifuge. The higher the concentration of the emulsifier lecithin and CMC added, it will be more stable because the emulsifier can reduce the surface tension so that the emulsion will coalesce. Adding an emulsifier will make the bond between the fat and water stronger. The emulsifier will be dispersed in water so that the hydrophilic part will absorb water. Water previously moving freely outside the grains will become bound. The theory shows that it causes the emulsifier to be more stable [18].

Based on the stability analysis of the mayonnaise emulsion, this variable has an average value of 2.56 and a standard deviation of 0.83 . The results showed that the standard deviation value was smaller than the value average.

\section{Viscosity analysis of mayonnaise}

The difference in the viscosity of mayonnaise corresponds to the increasing concentration of vegetable oil and the emulsifier added. The difference in viscosity/viscosity can also be caused by the type of vegetable oil used, with the characteristics of each vegetable oil being different. This theory is in line with the opinion of Setyawardhani et al. that each type of vegetable oil has different characteristics depending on the fatty acid content contained in it besides vegetable oil which acts as an internal phase that greatly affects the viscosity of mayonnaise so that at different concentrations it will make a difference to the viscosity of mayonnaise [21]. The viscosity (cP) value of mayonnaise is shown in Table 4.

Table 4 shows a difference in the level of viscosity or viscosity of the mayonnaise with the addition of corn lecithin emulsifier. The table above shows that the $\mathrm{L} 3 \mathrm{C} 3$ treatment has a greater viscosity level than the $2.1 \mathrm{cP}$. Commercial lecithin is used as an emulsifier, and lecithin effectively lowers the interfacial tension between fat and water but can maintain the stability of the emulsion in the dough. In addition, the lecithin emulsifier can reduce friction on the sugar fat, thus preventing the formation of solid lumps. Therefore, the greater the concentration of lecithin added, the greater the viscosity of mayonnaise. The standard mayonnaise viscosity in the market is $3346.7 \mathrm{cP}$ [22].

Meanwhile, in the research conducted by the author, the best viscosity was $2.12 \mathrm{cP}$, which indicates that it is still far from the viscosity of mayonnaise on the market and still unable to be used commercially. According to SNI (Indonesian National Standard), 01$4473-1998$, the mayonnaise viscosity standard is $2540 \mathrm{cP}$ (Indonesian National Standardization Agency, 1998). 
Table 4. Viscosity (CP) of mayonnaise with the addition of corn lecithin

\begin{tabular}{lcccccc}
\hline $\begin{array}{c}\text { Run } \\
\text { (Code) }\end{array}$ & $\begin{array}{c}\text { Empty pycnometer } \\
\text { weight }(\mathrm{g})\end{array}$ & $\begin{array}{c}\text { Fill in the weight } \\
\text { of the pycnometer }(\mathrm{g})\end{array}$ & $\begin{array}{c}\text { Pycnometer } \\
\text { volume }(\mathrm{mL})\end{array}$ & $\begin{array}{c}\text { Sample density } \\
(\mathrm{g} / \mathrm{mL})\end{array}$ & $\begin{array}{c}\text { Time } \\
(\text { second })\end{array}$ & $\begin{array}{c}\text { Viscosity } \\
(\mathrm{cP})\end{array}$ \\
\hline L1C1 & 26.91 & 50.91 & 25 & 0.96 & 1.7 & 1.63 \\
L1C2 & 26.91 & 51.93 & 25 & 1.0008 & 1.7 & 1.701 \\
L1C3 & 26.91 & 51.85 & 25 & 0.99 & 1.74 & 1.73 \\
L2C1 & 26.91 & 51.05 & 25 & 0.96 & 1.8 & 1.73 \\
L2C2 & 26.91 & 52.01 & 25 & 1.004 & 1.78 & 1.78 \\
L2C3 & 26.91 & 53.54 & 25 & 1.06 & 1.71 & 1.82 \\
L3C1 & 26.91 & 51.03 & 25 & 0.96 & 1.89 & 1.82 \\
L3C2 & 26.91 & 53.59 & 25 & 1.06 & 1.9 & 2.02 \\
L3C3 & 26.91 & 52.22 & 25 & 1.01 & 2.1 & $2.12^{*}$ \\
\hline Average & & & & & & 1.82 \\
SD & & & & & & 0.14 \\
\hline
\end{tabular}

Note: $\left(^{*}\right)=$ The best result

Based on research conducted, the author is still far from the established SNI. Based on the viscosity analysis of mayonnaise, the variable has an average value of 1.82 and a standard deviation of 0.14 . The results showed that the standard deviation value was smaller than the value average.

\section{Surface Tension Analysis on Mayonnaise}

The expected product from the use of corn lecithin is to reduce surface tension. The surface-active agent, in this case, lecithin as an emulsifier, is oriented at the interface that will gradually decrease the surface tension over time and the addition of the surface-active agent until a constant value is reached [23]. The value of surface tension $(\mathrm{N} / \mathrm{m})$ on mayonnaise is shown in Table 5 .

Table 5 shows that the $\mathrm{L} 3 \mathrm{C} 3$ treatment has a smaller surface tension value than the others, equal to $0.001 \mathrm{~N} / \mathrm{m}$. Crude lecithin is usually obtained from soybeans and egg yolks. This lecithin is a mixture of lipids (phospholipids) with phosphatidylcholine, ethanolamine, and inositol as the main components. Commercially, phospholipids are mainly obtained as a by-product in the production of vegetable oils. Therefore, the more lecithin is added, the decrease in surface tension will occur [16]. If one of the liquid interfacial tension decreases, it will facilitate the fluid phase to separate [24]. Emulsion stability with surface tension has a negative or opposite correlation, in that a high stabilizer concentration can cause the surface tension to decrease until it reaches a constant interface
Table 5. Surface tension $(\mathrm{N} / \mathrm{m})$ on mayonnaise with the addition of corn lecithin

\begin{tabular}{lccc}
\hline $\begin{array}{c}\text { Run } \\
\text { (Code })\end{array}$ & $\begin{array}{c}\text { Sample density } \\
(\mathrm{g} / \mathrm{mL})\end{array}$ & $\begin{array}{c}\text { Sample height } \\
(\mathrm{cm})\end{array}$ & $\begin{array}{c}\text { Surface tension } \\
\left(\times 10^{3} \mathrm{~N} / \mathrm{m}\right)\end{array}$ \\
\hline L1C1 & 0.96 & 0.02 & 3.36 \\
L1C2 & 1.0008 & 0.02 & 2.80 \\
L1C3 & 0.99 & 0.02 & 2.79 \\
L2C1 & 0.96 & 0.01 & 2.03 \\
L2C2 & 1.004 & 0.01 & 1.69 \\
L2C3 & 1.06 & 0.01 & 1.64 \\
L3C1 & 0.96 & 0.01 & 1.62 \\
L3C2 & 1.06 & 0.01 & 1.49 \\
L3C3 & 1.01 & 0.01 & 1.42 \\
\hline Average & & & 2.09 \\
SD & & & 0.71 \\
\hline
\end{tabular}

Note: $\left({ }^{*}\right)=$ The best result

tension and the emulsion stability is maintained. Based on the surface tension analysis on mayonnaise, the variable has an average value of $2.09 \pm 0.71 \times 10^{-3} \mathrm{~N} / \mathrm{m}$. The results showed that the standard deviation value was smaller than the value average.

\section{Organoleptic Analysis}

Organoleptic test on food panelists, namely mayonnaise with the addition of corn lecithin. The tests carried out included the color, taste, smell, and texture of the mayonnaise.

\section{Color}

Organoleptic test results on color for mayonnaise 
with corn lecithin and CMC are shown in Table 6.

Color is a very important physical parameter of food. The consumer's preference for food products is also determined by color because the product's color is the first attribute seen by consumers. Table 6 shows the color aspect; run 9 got the highest average score among the others, namely 4.4 , followed by the notation "a" and also the second-highest score was obtained by run 6 with an average score of 4.3 and also followed by the notation "a" which means both panelists prefer treatment with run 9 and 6 . The theory shows that the higher the concentration of lecithin emulsifier added, the lower the brightness level. Meanwhile, the addition of a CMC emulsifier shows that a CMC emulsifier also affects the increase in color brightness [18]. The addition of the lecithin emulsifier has a yellow color, which affects the color of the final mayonnaise product.

\section{Taste}

Organoleptic test results on the taste for mayonnaise with the addition of corn lecithin and CMC are shown in Table 7.

Table 7 shows that in terms of taste, run 9 gets the highest score among the others, namely 3.2 , with the following notation "a", which means that the panelists prefer the treatment on running 9. The theory suggests that mayonnaise with the addition of lecithin emulsifier has an unpleasant taste. It was derived from corn oil extract, thus reducing the taste preferences of the panelists, while the addition of a CMC emulsifier has an increasing tendency. CMC is a cellulose derivative with a sweetness level of $69 \%$ so that with the addition of the CMC emulsifier, the panelists' preference for taste increases [18]. However, in terms of taste, the highest score obtained does not get the maximum value. The result shows that the resulting taste is not as strong as the typical taste of mayonnaise in the market, so that the level of preference for neutral consumers leads to somewhat like it.

\section{Smell}

The results of the organoleptic test on smell for mayonnaise with the addition of corn lecithin and CMC are shown in Table 8.
Table 8 shows that in terms of smell or aroma, run 9 gets the highest score among the others, namely 4 with the following notation "a", which means that the panelists prefer the treatment on running 9 . The theory

Table 6. Panelists average preferred level of mayonnaise color with the addition of corn lecithin and CMC

\begin{tabular}{lcc}
\hline Treatment & Average color value & Notation \\
\hline Run 1 & 1.4 & $\mathrm{~d}$ \\
Run 2 & 2.3 & $\mathrm{c}$ \\
Run 3 & 2.9 & $\mathrm{bc}$ \\
Run 4 & 3.1 & $\mathrm{~b}$ \\
Run 5 & 3.4 & $\mathrm{~b}$ \\
Run 6 & 4.3 & $\mathrm{a}$ \\
Run 7 & 2.9 & $\mathrm{bc}$ \\
Run 8 & 3 & $\mathrm{~b}$ \\
Run 9 & $4.4^{\star}$ & $\mathrm{a}$ \\
\hline
\end{tabular}

Table 7. Average levels of panelists preference to mayonnaise flavor with the addition of corn lecithin and CMC

\begin{tabular}{lcc}
\hline Treatment & Average taste score & Notation \\
\hline Run 1 & 1.5 & $\mathrm{~b}$ \\
Run 2 & 1.6 & $\mathrm{~b}$ \\
Run 3 & 1.7 & $\mathrm{~b}$ \\
Run 4 & 1.7 & $\mathrm{~b}$ \\
Run 5 & 3 & $\mathrm{a}$ \\
Run 6 & 3 & $\mathrm{a}$ \\
Run 7 & 2.9 & $\mathrm{a}$ \\
Run 8 & 2.9 & $\mathrm{a}$ \\
Run 9 & $3.2^{*}$ & $\mathrm{a}$ \\
\hline
\end{tabular}

Table 8. The panelists average preferred level of mayonnaise odor with the addition of corn lecithin and CMC

\begin{tabular}{lcc}
\hline Treatment & Average smell value & Notation \\
\hline Run 1 & 1.6 & $\mathrm{~d}$ \\
Run 2 & 1.9 & $\mathrm{~d}$ \\
Run 3 & 1.9 & $\mathrm{~d}$ \\
Run 4 & 2.1 & $\mathrm{~d}$ \\
Run 5 & 2.2 & $\mathrm{~cd}$ \\
Run 6 & 3.1 & $\mathrm{~b}$ \\
Run 7 & 2.9 & $\mathrm{bc}$ \\
Run 8 & 2.9 & $\mathrm{bc}$ \\
Run 9 & $4^{*}$ & $\mathrm{a}$ \\
\hline
\end{tabular}


suggests that the $\mathrm{CMC}$ is in powder form, white, odorless, and tasteless so that it does not affect the product's aroma, while the lecithin emulsifier has a slightly unpleasant aroma that can affect the aroma of mayonnaise [18]. This study's results follow the research which states that the consumer has given a normal or neutral rating to the unscented mayonnaise. The result shows that the aroma of mayonnaise is not as strong as the aroma of mayonnaise. The aroma shows sensory properties that require sensitivity to taste and smell food, and also, the aroma of food can form delicacy and is more related to the sense of smell.

\section{Texture}

Organoleptic test results on texture for mayonnaise with corn lecithin and CMC are shown in Table 9.

Table 9 shows that in terms of smell or aroma, run 9 gets the highest score among the others, which is 3.8 with the following notation "a", which means that the panelists prefer the treatment on running 9. Also, CMC has a higher value. It is higher compared to the addition of lecithin emulsifier, although it is not too significant. The texture that panelists prefer is the one that is easier to smear [18]. Consumers who like the texture may feel that the resulting texture is closer to the typical mayonnaise texture, which is semi-solid. The texture of mayonnaise is very thick and soft, which consumers prefer compared to the watery texture [25]. The authors' research supports this, where run 9 has a thicker texture due to the addition of corn lecithin and CMC.

Table 9. Panelists average preferred level of mayonnaise texture with the addition of corn lecithin and CMC

\begin{tabular}{lcc}
\hline Treatment & Texture value average & Notation \\
\hline Run 1 & 1.4 & $\mathrm{e}$ \\
Run 2 & 1.8 & $\mathrm{de}$ \\
Run 3 & 2.1 & cde \\
Run 4 & 2.2 & cde \\
Run 5 & 2.4 & $\mathrm{bcd}$ \\
Run 6 & 2.8 & $\mathrm{bc}$ \\
Run 7 & 3.1 & $\mathrm{ab}$ \\
Run 8 & 2.9 & $\mathrm{bc}$ \\
Run 9 & $3.8^{*}$ & $\mathrm{a}$ \\
\hline
\end{tabular}

\section{- CONCLUSION}

Based on the results obtained, in the analysis of corn lecithin emulsifier for GC-MS analysis, the largest content of corn lecithin emulsifier was palmitic acid (hexadecanoic acid), with its content of $44.79 \%$. In contrast, FTIR analysis had almost the same absorbance pattern in specific absorption areas for lecithin. The L3C3 treatment was obtained in the mayonnaise analysis, namely $60 \%$ fat content, $4 \%$ emulsion stability, $2.12 \mathrm{cP}$ viscosity, and $0.00141736 \mathrm{~N} / \mathrm{m}$ surface tension, which were the best results. The results of the organoleptic research showed that the panelists' preferred values of mayonnaise with $\mathrm{L} 3 \mathrm{C} 3$ treatment were color 4.4 (like), taste 3.2 (sufficient like), smell 4 (like), and texture 3.8 (like it).

\section{- ACKNOWLEDGMENTS}

The author would like to thank all parties in the Nutrition Laboratory and Food Technology Laboratory of Diponegoro University.

\section{- REFERENCES}

[1] Nissa, C., Arifan, F., Febrianto, R., Aditya, W., Dwimawanti, I.H., and Widyasmara, R.P., 2019, Effect of sugar on nutrient composition and shelf life of red guava jams, IOP Conf. Ser.: Earth Environ. Sci., 406, 012027.

[2] Reckziegel, Y., 2015, Characterization and Comparison of The Functionality of Fractionated Lecithin from Different Sources, Thesis, Universiteit Gent, Ghent, Belgium.

[3] Robert, C., Couëdelo, L., Vaysse, C., and Michalski, M.C., 2020, Vegetable lecithins: A review of their compositional diversity, impact on lipid metabolism and potential in cardiometabolic disease prevention, Biochimie, 169, 121-132.

[4] Hamad, A., Septhea, G.A., and Ma'ruf, A., 2005, Kemampuan daya emulsifier corn lecithin yang dihasilkan dari water degumming process minyak jagung, J. Inov. Tek. Kim., 1 (2), 88-92.

[5] Thakur, S., and Gogate, P.R., 2020, Synthesis of $\mathrm{Pd} / \mathrm{C}$ catalyst using formaldehyde reduction method 
and application for ultrasound assisted transfer hydrogenation of corn oil, Chem. Eng. Process., 152, 107939.

[6] Sun, X., Zhang, L., Tian, S., Yang, K., and Xie, J., 2020, Phospholipid composition and emulsifying properties of rice bran lecithin from enzymatic degumming, $L W T, 117,108588$.

[7] Okuro, P.K., Gomes, A., Costa, A.L.R., Adame, M.A., and Cunha, R.L., 2019, Formation and stability of W/O-high internal phase emulsions (HIPEs) and derived $\mathrm{O} / \mathrm{W}$ emulsions stabilized by PGPR and lecithin, Food Res. Int., 122, 252-262.

[8] Tavernier, I., Wijaya, W., Van der Meeren, P., Dewettinck, K., and Patel, A.R., 2016, Food-grade particles for emulsion stabilization, Trends Food Sci. Technol., 50, 159-174.

[9] Evanuarini, H., Nurliyani, N., Indratiningsih, I., and Hastuti, P., 2019, Kestabilan emulsi dan oksidasi low fat mayonnaise menggunakan kefir sebagai alternatif emulsifier, JIIP, 29 (1), 83-94.

[10] Paisan, S., Chetpattananondh, P., and Chongkhong, S., 2017, Assessment of water degumming and acid degumming of mixed algal oil, J. Environ. Chem. Eng., 5 (5), 5115-5123.

[11] Balcaen, M., Steyls, J., Schoeppe, A., Nelis, V., and Van der Meeren, P., 2021, Phosphatidylcholinedepleted lecithin: A clean-label low-HLB emulsifier to replace PGPR in w/o and w/o/w emulsions, $J$. Colloid Interface Sci., 581, 836-846.

[12] Gunstone, F.D., 2011, "Production and Trade of Vegetable Oils" in Vegetable Oils in Food Technology: Composition, Properties and Uses, $2^{\text {nd }}$ Ed., John Wiley \& Sons, Ltd, Hoboken, 1-24.

[13] Barrera-Arellano, D., Badan-Ribeiro, A.P., and Serna-Saldivar, S.O., 2018, "Corn Oil: Composition, Processing, and Utilization" in Corn, $3^{\text {rd }}$ Ed., AACC International Press, Oxford, 593-613.

[14] Sadhukhan, S., Bhattacharjee, A., Sarkar, U., Baidya, P.K., and Baksi, S., 2018, Simultaneous degumming and production of a natural gum from Crotalaria juncea seeds: Physicochemical and rheological characterization, Int. J. Biol. Macromol., 111, 967975.

[15] Nzai, J.M., and Proctor, A., 1999, Soy lecithin phospholipid determination by Fourier transform infrared spectroscopy and the acid digest/arsenomolybdate method: A comparative study, J. Am. Oil Chem. Soc., 76 (1), 61-66.

[16] Zaouadi, N., Cheknane, B., Hadj-Sadok, A., Canselier, J.P., and Hadj Ziane, A., 2015, Formulation and optimization by experimental design of low-fat mayonnaise based on soy lecithin and whey, J. Dispersion Sci. Technol., 36 (1), 94-102.

[17] Kim, J.S., Kim, M.J., and Lee, J.H., 2018, The critical micelle concentration of lecithin in bulk oils and medium chain triacylglycerol is influenced by moisture content and total polar materials, Food Chem., 261, 194-200.

[18] Fitriyaningtyas, S.I., and Widyaningsih, T.D., 2015, Pengaruh penggunaan lesitin dan CMC terhadap sifat fisik, kimia, dan organoleptik margarin sari apel manalagi (Malus sylfertris Mill) tersuplementasi minyak kacang tanah, Jurnal Pangan dan Agroindustri, 3 (1), 226-236.

[19] Gaonkar, G., Koka, R., Chen, K., and Campbell, B., 2010, Emulsifying functionality of enzymemodified milk proteins in $\mathrm{O} / \mathrm{W}$ and mayonnaiselike emulsions, Afr. J. Food Sci., 4 (1), 16-25.

[20] Delacharlerie, S., Petrut, R., Deckers, S., Flöter, E., Blecker, C., and Danthine, S., 2016, Structuring effects of lecithins on model fat systems: A comparison between native and hydrolyzed forms, LWT Food Sci. Technol., 72, 552-558.

[21] Setyawardhani, D.A., Sulistyo, H., Sediawan, W.B., and Fahrurrozi, M., 2016, Peranan waktu pengadukan terhadap karakteristik kompleksasi urea sebagai sarana pemisahan asam lemak omega dari minyak nabati, Reaktor, 16 (2), 81-86.

[22] Al-Bachir M.Z.R., 2006, Effect of gamma irradiation on some characteristics of shell eggs and mayonnaise prepared from irradiated from irradiated eggs, J. Food Saf., 26 (4), 348-360. 
[23] Lachman, L., Lieberman, H.A., and Kanig, J.L., 1991, The Theory and Practice of Industrial Pharmacy, $3^{\text {rd }}$ Ed., Varghese Publishing House, India.

[24] Erfando, T., Khalid, I., and Bahari, R., 2021, Experimental of alternative demulsifier formulation from corn oil in overcoming water-oil emulsion,
Mater. Today: Proc., 39, 1061-1064.

[25] Thakur, S., and Gogate, P.R., 2020, Synthesis of $\mathrm{Pd} / \mathrm{C}$ catalyst using formaldehyde reduction method and application for ultrasound assisted transfer hydrogenation of corn oil, Chem. Eng. Process., 152, 107939. 